\title{
Preserved leftward movement in left unilateral spatial neglect due to frontal lesions
}

\author{
Sumio Ishiai, Sadakiyo Watabiki, Eiai Lee, Tadashi Kanouchi, Natsu Odajima
}

\begin{abstract}
Three patients with left unilateral spatial neglect after predominantly frontal lobe lesions were asked to extend a horizontal line leftwards to double its original length. In this line extension task, they readily executed movements in or towards the contralesional left space. They performed the task in the left and right hemispaces as well as in the midline. The mean extension lengths did not differ significantly among these three spatial conditions. These results suggest that directional hypokinesia takes little part in left unilateral spatial neglect due to frontal lobe lesions. It is considered that the patients could execute leftward movements as the task oriented their attention sufficiently to the left. Two of the three patients, like reported cases with frontal neglect, showed a typical exploratory deficit for the left space in the line cancellation test. Such a deficit found in the traditional tasks, however, does not mean the presence of directional hypokinesia. All three patients showed visual extinction on double simultaneous stimulation. An attentional mechanism seems to play a predominant part in unilateral spatial neglect due to frontal lesions.
\end{abstract}

\section{(F Neurol Neurosurg Psychiatry 1994;57:1085-1090)}

Unilateral spatial neglect is the failure of brain damaged patients to attend to and explore stimuli presented in the space contralateral to their lesions. ${ }^{12}$ Neglect in humans usually occurs after right hemispheric lesions that involve the parietal lobe, ${ }^{1-4}$ whereas in monkeys, it is a classical finding that neglect is produced by frontal lobe lesions. ${ }^{56}$ Since the report of Heilman and Valenstein, ${ }^{7}$ however, frontal lobe lesions have also been known to cause unilateral spatial neglect in humans, ${ }^{389}$ although frontal neglect is infrequent compared with parietal neglect. ${ }^{4}$

Recent theories of unilateral spatial neglect consider that neglect is a complex deficit with multiple components, such as attentional, exploratory-motor, and representational disorders. ${ }^{12}$ According to Mesulam's cortical network theory for directed attention, ${ }^{1011}$ the frontal region centred around the frontal eye field provides a mechanism for scanning and exploring. Because the regions contributing to directed attention are tightly interconnected, frontal lesions may produce multicomponent neglect in which exploratory motor deficit is relatively stressed. Several studies ${ }^{12-15}$ reported that exploratory motor deficit or directional

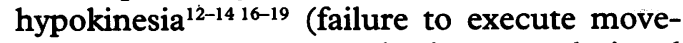
ments fully in or towards the contralesional space) predominates in unilateral spatial neglect after lesions that involve the frontal lobe as well as the parietal lobe. A few patients with restricted frontal lesions ${ }^{20-22}$ showed exploratory neglect without other obvious signs of neglect.

Recently, Ishiai et al ${ }^{23}$ examined patients with neglect and with right parietal lobe lesions by means of a line extension task and showed that directional hypokinesia takes little part in left unilateral spatial neglect. The patients accurately extended a line leftwards to double its original length, whatever the severity of neglect found in the line bisection test. They were considered to execute movements in or towards the contralesional space as the task oriented their attention sufficiently to the left. The present study applied the line extension task to three patients with unilateral spatial neglect due to predominantly frontal lobe lesions to test if they had directional hypokinesia and failed to perform the line extension task.

\section{Methods}

LINE BISECTION TEST

All the subjects were first given a series of line bisection tests. ${ }^{23} \mathrm{~A}$ line 200 or $100 \mathrm{~mm}$ long was drawn horizontally across the centre of a piece of A4 $(210 \times 297 \mathrm{~mm})$ paper. Three spatial conditions were examined: For the centre condition, the paper with its line was placed so that its centre lay in the sagittal midplane of the subject's trunk. For the right and left conditions respectively, the left and right edges of the paper were positioned in the sagittal midplane of the trunk. The examiner explained how to mark the centre by showing an ideal bisection of a line, then asked the subjects to bisect the lines presented in an order randomised across the three spatial conditions and the two lengths. Each subject bisected eight lines for each length in each of the three spatial conditions, thereby completing 48 trials.

\section{LINE EXTENSION TASK}

After completion of the set of line bisections, the subjects were tested for their ability to extend a line leftwards to double its original length. ${ }^{23}$ A horizontal line 100 or $50 \mathrm{~mm}$ long 


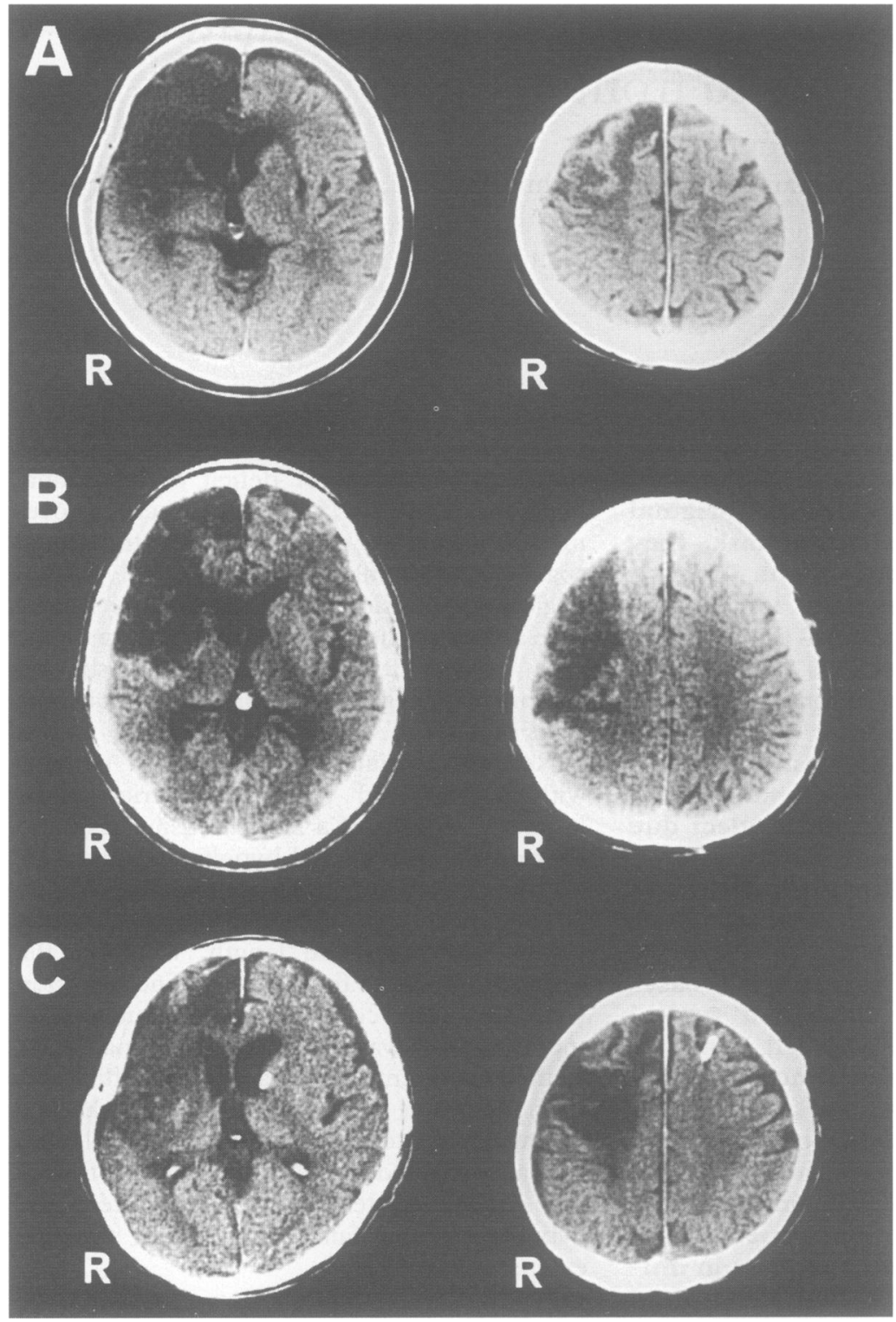

$C T$ showing the predominantly frontal lesions of cases $1(A), 2(B)$, and $3(C)$. Left is on the right of the images. length in each of the three spatial conditions, thereby completing 48 trials.

\section{Case reports}

All patients gave informed consent to participate in this study.

\section{CASE 1}

A 63 year old right handed woman had a stroke on 19 December 1989. The present examination was performed nine months after the onset. At this time, CT showed an infarction that involved almost all the right frontal lobe and its subcortical structures, as well as the anterior part of the right temporal lobe (figure, A). The patient had a left hemiplegia and a left sided moderate sensory loss. There was no visual field defect on confrontation testing. She exhibited left sided visual extinction, however, on bilateral simultaneous stimulation. Typical left unilateral spatial neglect was found on neuropsychological examination. She omitted left sided 15 of 30 lines in the line cancellation test ${ }^{24} 25$ and copied only the right half of a figure of a daisy. ${ }^{126}$ In the line bisection test ${ }^{2627}$ with lines $200 \mathrm{~mm}$ long, she placed the mark about $15 \mathrm{~mm}$ to the right of the true midpoint.

CASE 2

A 59 year old right handed man suddenly developed a left hemiplegia and a left sided moderate sensory loss on 22 July 1990 . The present examination was undertaken a month after onset. CT at this time revealed an infarction that involved almost all the right dorsolateral frontal lobe and its subcortical structures, as well as the insula (figure, B). The lesion extended to the postcentral gyrus. The patient had no visual field defect but showed visual extinction, omitting about $50 \%$ of the left sided targets on bilateral simultaneous stimulation. Typical left unilateral spatial neglect was found on neuropsychological examination. He copied only the right half of a daisy and omitted left sided 15 of 30 lines in the line cancellation test. When bisecting $200 \mathrm{~mm}$ lines, he placed the mark about $10 \mathrm{~mm}$ to the right of the true midpoint.

CASE 3

A 66 year old right handed man was admitted to hospital with a sudden headache on 16 August 1992. CT and angiography showed the rupture of an aneurysm of the anterior communicating artery. An operation on the aneurysm was performed next day and an apparent left hemiparesis appeared six days later. The present examination was performed seven months after the operation. At this time, CT showed an infarction that involved almost all the right frontal lobe and its subcortical structures, as well as the anterior half of the right temporal lobe (figure, $\mathrm{C}$ ). The patient had no visual field defect but showed left sided visual extinction on bilateral simultaneous stimulation. Mild left unilateral spatial neglect was found on neuropsychological examination. He copied all the petals of a 
Table 1 Deviations from true midpoint in the line bisection test

\begin{tabular}{|c|c|c|c|c|c|c|c|}
\hline \multirow[b]{2}{*}{ Case } & \multicolumn{3}{|c|}{ Spatial condition } & \multirow{2}{*}{$\begin{array}{l}\text { Kruskal- } \\
\text { Wallis } \\
\text { test }\end{array}$} & \multicolumn{3}{|c|}{ Post hoc comparisons } \\
\hline & Left & Centre & Right & & $L v C$ & $C v R$ & $L v R$ \\
\hline $\begin{array}{l}1 \\
2 \\
3\end{array}$ & $\begin{array}{r}18 \cdot 5(7 \cdot 4) \\
8 \cdot 0(5 \cdot 5) \\
30 \cdot 1(3 \cdot 9)\end{array}$ & $\begin{array}{r}13 \cdot 8(5 \cdot 8) \\
9 \cdot 8(4 \cdot 8) \\
20.6(7 \cdot 8)\end{array}$ & $\begin{array}{r}0.5(7 \cdot 3) \\
1.6(4 \cdot 8) \\
-4.8(9 \cdot 5)\end{array}$ & $\begin{array}{l}\quad 200 \mathrm{~mm} \text { line } \\
\mathrm{p}<0.001 \\
\mathrm{p}<0.025 \\
\mathrm{p}<0.001\end{array}$ & $\begin{array}{l}\text { NS } \\
\text { NS } \\
\text { NS }\end{array}$ & $\begin{array}{l}\mathrm{p}<0.01 \\
\mathrm{p}<0.01 \\
\mathrm{p}<0.01\end{array}$ & $\begin{array}{l}p<0.01 \\
p<0.05 \\
p<0.01\end{array}$ \\
\hline $\begin{array}{l}1 \\
2 \\
3\end{array}$ & $\begin{array}{r}5 \cdot 3(4 \cdot 1) \\
3.5(1 \cdot 7) \\
15 \cdot 6(2 \cdot 9)\end{array}$ & $\begin{array}{l}2.9(3.6) \\
1.9(1.0) \\
5.6(3.3)\end{array}$ & $\begin{array}{l}-2.7(4.3) \\
-2.6(2.1) \\
-4.9(5 \cdot 2)\end{array}$ & $\begin{array}{l}\quad 100 \mathrm{~mm} \text { line } \\
\mathrm{p}<0.025 \\
\mathrm{p}<0.001 \\
\mathrm{p}<0.001\end{array}$ & $\begin{array}{l}\text { NS } \\
\text { NS } \\
p<0.05\end{array}$ & $\begin{array}{l}p<0.05 \\
p<0.01 \\
p<0.05\end{array}$ & $\begin{array}{l}p<0.01 \\
p<0.01 \\
p<0.01\end{array}$ \\
\hline
\end{tabular}

Values are means (SD).

daisy but omitted its left leaf. Although the copying of a daisy was examined only once, the omission of the easily recognisable left leaf (40 $\mathrm{mm}$ long and $16 \mathrm{~mm}$ wide) was considered to show the presence of neglect. Thirty age matched control subjects never omitted this part of the figure. He placed the mark about $20 \mathrm{~mm}$ to the right of the true midpoint when bisecting $200 \mathrm{~mm}$ lines. In the line cancellation test, however, he marked all the lines.

\section{Results}

LINE BISECTION TEST

The distance between the true midpoint and the mark showing the subjective midpoint was measured to the closest millimetre and expressed as positive if the mark deviated to the right. Table 1 shows the mean deviations from the true midpoint and the statistical results concerning the spatial effect for each patient. All the three cases placed the mark to the right of the true midpoint in the left and centre conditions for both the 200 and 100 $\mathrm{mm}$ lines. The mean deviations found in these bisections were significantly greater than those of the 10 age matched normal controls in our previous study. ${ }^{23}$ The mean deviations of the normal controls for the $200 \mathrm{~mm}$ lines were $1 \cdot 1(\mathrm{SD} 2 \cdot 1) \mathrm{mm}, 1 \cdot 3(2 \cdot 4) \mathrm{mm}$, and $2 \cdot 1$ (3.2) $\mathrm{mm}$ for the left, centre, and right conditions respectively, and those for the $100 \mathrm{~mm}$ lines were $0.4(\mathrm{SD} 1.5) \mathrm{mm}, 0.5(1.4) \mathrm{mm}$, and $0.6(1.3) \mathrm{mm}$. When bisecting $200 \mathrm{~mm}$ lines in the right condition, cases 1 and 2 marked near the true midpoint and case 3 marked to the left of it. When bisecting 100 $\mathrm{mm}$ lines in the right condition, all the three cases marked slightly to the left of the true midpoint. The mean deviations were significantly different among the three spatial conditions for each of the two lengths for each case
(Kruskal-Wallis test). Post hoc comparisons (non-parametric equivalent of Williams' test $^{28}$ ) showed that the mean deviations were significantly greater for the centre than for the right condition and for the left than for the right condition.

LINE EXTENSION TASK

The length of the overextension was calculated by subtracting the ideal extension ( 100 or $50 \mathrm{~mm}$ ) from the length of subject's extension measured to the closest millimetre. When the extension was less than the ideal length, the calculated value was treated as a negative overextension. Table 2 shows the mean overextensions and the statistical results concerning the spatial effect for each patient. The mean overextensions were all positive for each spatial condition for each line length. In our previous study, ${ }^{23}$ the mean overextensions of the $100 \mathrm{~mm}$ lines of the 10 normal controls were $0.6(\mathrm{SD} 4.0) \mathrm{mm}, 1.8(4.0) \mathrm{mm}$, and 2.5 (4.3) $\mathrm{mm}$ for the left, centre, and right conditions respectively. Those of the $50 \mathrm{~mm}$ lines were $2 \cdot 2(\mathrm{SD} 6 \cdot 2) \mathrm{mm}, 2 \cdot 2(6 \cdot 1) \mathrm{mm}$, and $2 \cdot 8$ (4.9) $\mathrm{mm}$. The three cases of the present study extended the $100 \mathrm{~mm}$ lines significantly longer (about $10 \mathrm{~mm}$ ) than the normal controls except when cases 2 and 3 extended the lines almost accurately in the centre and right conditions respectively. In the extension of 50 $\mathrm{mm}$ lines, the mean overextension for each spatial condition was within the mean \pm 2 SDs of the normal controls. The effect of the three spatial conditions was not significant for each length for each case (Kruskal-Wallis test).

\section{Discussion}

The three patients showed left unilateral spatial neglect after predominantly frontal lobe lesions. Their lesions extended to the postcentral gyrus or the subcortical structures, but

Table 2 Overextensions in the line extension task

\begin{tabular}{|c|c|c|c|c|c|c|c|}
\hline \multirow[b]{2}{*}{ Case } & \multicolumn{3}{|c|}{ Spatial condition } & \multirow{2}{*}{$\begin{array}{l}\text { Kruskal- } \\
\text { Wallis } \\
\text { test }\end{array}$} & \multicolumn{3}{|c|}{ Post hoc comparisons } \\
\hline & Left & Centre & Right & & $L v C$ & $C v R$ & $L v R$ \\
\hline \multicolumn{8}{|c|}{$100 \mathrm{~mm}$ line } \\
\hline 1 & $12 \cdot 8(4 \cdot 6)$ & $12 \cdot 9(3 \cdot 7)$ & $12 \cdot 5(3 \cdot 2)$ & NS & NS & NS & NS \\
\hline 2 & $13.0(13 \cdot 4)$ & $3.5(7.9)$ & $11.8(8.6)$ & NS & NS & NS & NS \\
\hline 3 & $11.7(10.9)$ & $13 \cdot 4(7 \cdot 9)$ & $9 \cdot 8(10 \cdot 3)$ & NS & NS & NS & NS \\
\hline \multicolumn{8}{|c|}{$50 \mathrm{~mm}$ line } \\
\hline 1 & $2.5(1.9)$ & $0 \cdot 1(4 \cdot 1)$ & $4 \cdot 0(8 \cdot 3)$ & NS & NS & NS & NS \\
\hline 2 & $4 \cdot 8(8 \cdot 6)$ & $11 \cdot 6(12 \cdot 6)$ & $5 \cdot 1(7 \cdot 5)$ & NS & NS & NS & NS \\
\hline 3 & $6 \cdot 1(6 \cdot 4)$ & $6.0(5.9)$ & $8.3(8.9)$ & NS & NS & NS & NS \\
\hline
\end{tabular}

Values are means (SD). 
not to the parietal region around the inferior parietal lobule, where lesions are known to cause unilateral spatial neglect. ${ }^{1-4}$ They readily executed leftward movements in the line extension task, in which they had to extend a line leftwards to double its original length. There was no significant difference in the length of line extension among the left, centre, and right conditions, although the line bisection errors were affected by these spatial conditions, as Heilman et al ${ }^{17}$ reported. These results suggest that an exploratory motor component ${ }^{1011} 152022$ or directional hypokinesia $^{12-1417-1921}$ takes little part in left unilateral spatial neglect due to frontal lesions. As we did not record reaction times, our results do not exclude the type of directional hypokinesia reported by Heilman et al ${ }^{18}$-namely, prolonged reaction times for leftward movements. We found that the three patients started to extend the lines leftwards, however, immediately after presentation of the test sheets.

Absence of directional hypokinesia has been reported in neglect due to predominantly parietal lesions ${ }^{2329}$ but not in frontal neglect. In our line extension task, the patients seemed to look continually at the left extreme of the line during the process of leftward extension, as fixation usually centres on the pencil tip during manual drawing. ${ }^{23} 30$ Selection of a motor plan should automatically produce a shift of attention towards the spatial sector in which the action will be executed. $^{31}$ We thus consider that the patients could execute movements in or towards the contralesional space as the line extension task oriented their attention sufficiently to the left.

In the studies with traditional diagnostic tasks for neglect, several authors ${ }^{15}{ }^{20-22}$ have emphasised an exploratory motor component or directional hypokinesia in unilateral spatial neglect due to frontal lesions. The patients of Daffner et $a l^{20}$ and Bottini et $a l^{21}$ and patient 2 of Liu et $a l^{22}$ showed severe exploratory neglect without other obvious signs of neglect. Binder et $a l^{15}$ found that the combination of abnormal cancellation and normal line bisection was always associated with a frontal or basal ganglia localisation. We also found that two of the three patients with frontal lesions (cases 1 and 2) neglected the left hemispace typically in the line cancellation test but bisected the lines with small rightward errors. Case 3, however, who also had a large frontal lesion, marked all the lines in the line cancellation test, whereas his rightward bisection errors were greater than those of cases 1 and 2. Such a dissociation in performances in these two tasks has been reported in patients with lesions that involved the parietal lobe ${ }^{32}$ but not in patients with predominantly frontal lesions. Despite the variability of neglect manifestations, however, all the three patients readily executed leftward movements in the line extension task. These findings suggest that the traditional diagnostic tasks cannot distinguish among the components of mechanisms underlying unilateral spatial neglect. Not only unilateral spatial neglect itself but also insufficient motivation for tasks ${ }^{25}$ may affect performances in exploration tasks, such as the cancellation test. Our cases 1 and 2 showed improvement of left unilateral spatial neglect in the line cancellation test when motivated with the use of numbering of lines instead of simple crossing out.

Some experimental studies ${ }^{131433}$ tried to differentiate an exploratory motor component from an attentional component by decoupling the direction of a visual stimulus and the direction of hand or eye movement. The task of Bisiach et al ${ }^{13}$ was a modified line bisection task with an apparatus with pulleys. The task of Tegnér et al ${ }^{14}$ was a line cancellation task with a looking glass. These groups of authors suggested that the motor component or directional hypokinesia is more pronounced in patients with lesions involving the frontal lobe. The lesions of their patients were large, however, and involved the parietal lobe as well as the frontal lobe. The patient of Butter et $a l^{33}$ had a frontal infarction with only a slight extension to the postcentral gyrus. After left sided inattention abated, the patient showed directional hypokinesia of eye movement only when a stimulus on the right required a leftward eye movement. Although the deficits found in these crossed motor tasks seem to be explained by directional hypokinesia, other factors may affect the performances of patients with frontal lesions. The crossed motor tasks are difficult in that when patients desired to move the pointer for bisection ${ }^{13}$ or the hand image through mirror view ${ }^{14}$ to the right (or left), they had to move the hand oppositely to the left (or right). Some of the patients of Tegnér et al ${ }^{14}$ showed difficulties for hand movements towards either side in the mirror view condition. Frontal patients have difficulty in following rules ${ }^{34}$ and tend to continue their automatic action regardless of the instructions that they have just received. ${ }^{35}$ In the line extension task, the site and direction of motor execution correspond to those of attention as in the other typical tests for neglect, such as the line cancellation test, ${ }^{24} 25$ the line bisection test, ${ }^{26}{ }^{27}$ and the copying of figures. ${ }^{126}$ We therefore consider that absence of directional hypokinesia shown in the line extension task is convincing. The present study did not examine the three patients with the tasks of Bisiach et $a l^{13}$ and Tegnér et al. ${ }^{14}$ Further studies that contrast performances in these tasks and the line extension task should contribute to our understanding of the mechanisms of unilateral spatial neglect due to frontal lesions.

After a unilateral frontal eye field lesion, monkeys tend to deviate the eyes and the head towards the side of the lesion, show rare spontaneous eye movements contralateral to the lesion, and neglect stimuli in the contralateral space. ${ }^{56}$ Incapacity to move towards the contralesional stimuli cannot fully explain their unilateral spatial neglect. Latto and Cowey ${ }^{5}$ reported that these monkeys could not respond to visual stimuli presented contralateral to the lesion even when the required response was the pressing of a lever with the 
preferred hand. Rizzolatti et $a l^{6}$ reported that the presentation of contralesional threatening stimuli does not elicit emotional responses. Furthermore, after the oculomotor disturbance had disappeared, the monkeys still preferred the ipsilateral visual stimulus in the test with two stimuli in far space. In the present study, we examined all the three patients one month or more after onset. None of them showed any obvious deviation of the eyes or head towards the right. The range of eye movement was not restricted on routine neurological examination. All of them, like most of the reported cases with frontal neglect, ${ }^{792133}$ showed visual extinction on double simultaneous stimulation. Attentional mechanism ${ }^{1}$ thus seems to play a predominant part also in human unilateral spatial neglect due to frontal lesions. The results of the present study suggest that the underlying mechanism is essentially the same in frontal and parietal neglect. The patient of Daffner et al ${ }^{20}$ and patient 2 of Liu et $a l^{22}$ showed exploratory motor neglect but did not, however, exhibit visual extinction. They had smaller frontal lesions than our patients whose lesions involved most of the frontal lobe. To clarify the nature of frontal neglect in humans, we need further studies on patients with frontal lesions of various sizes and sites in either acute or chronic phase.

All the three frontal patients extended 50 $\mathrm{mm}$ lines accurately but extended $100 \mathrm{~mm}$ lines about $10 \mathrm{~mm}$ longer than the normal controls. Ishiai et $a l^{23}$ reported that the patients with unilateral spatial neglect due to parietal lesions accurately performed the line extension task for both line lengths (50 and $100 \mathrm{~mm}$ ), whatever the severity of neglect found in the line bisection test. Thus we do not consider that the excessive extensions by the patients with frontal lesions resulted from unilateral spatial neglect. The excessive extension might be caused by continuous perseverance $^{36}$ or visual grasp ${ }^{33} 37$ that was disengaged by frontal lesions, although at present, we do not know why it occurred for only the longer lines.

Patients with left unilateral spatial neglect sometimes bisect lines with greater deviations in the left hemispace than in the midline and in the midline than in the right hemispace. ${ }^{17} 23$ Our patients with frontal lesions also showed such a spatial effect in the line bisection test. As both the patients with frontal lesions and those with parietal lesions ${ }^{23}$ could readily execute leftward movements, directional hypokinesia cannot explain the spatial effect. This effect may result from attentional imbalance, ${ }^{38}$ with attention biased to the right side after right hemisphere damage. The leftward deviations found in our patients' bisection in the right condition, however, seem paradoxical to this explanation. Patients with neglect with parietal lesions may also occasionally show leftward bisection errors in the right hemispace. ${ }^{2326}$ Ishiai et al ${ }^{26}$ considered that unilateral spatial neglect cannot be excluded by the absence of rightward deviation, because they found the eye fixation pattern characteristic of unilateral spatial neglect in such bisections. They, however, analysed the eye fixation pattern only from the time of the first fixation on the stimulus line. What determines the point on the line at which patients with neglect first fixate remains unspecified. ${ }^{26}$ Marshall and Halligan $^{39}$ interpreted the line bisection performances of patients with neglect in terms of two constructs: the size of the Weber fraction $^{40}$ (the "just noticeable difference" between two magnitudes) and the attentional direction of approach to a psychological "indifference zone", the extent of which is determined by the Weber fraction. Patients with left unilateral spatial neglect may usually adopt a right to left scan track of attention and place the mark when the scan reaches the indifference zone that is expanded consequent on cerebral damage. When asked to bisect a line in the right hemispace, however, our patients had first to search toward the right space where the line was presented, as they showed no deviation of the eyes or head when no visual stimulus was presented. According to the interpretation by Marshall and Halligan, ${ }^{39}$ in the right condition, they may have approached from the left endpoint to the indifference zone and placed the subjective midpoint to the left of the true midpoint. Once neglect patients fixate a point on the line, they tend to persist with this point. ${ }^{26}$ The first rightward search may thus have had a strong effect on the bisection in the right hemispace.

1 Heilman KM, Watson RT, Valenstein E. Neglect and related disorders. In: Heilman $\mathrm{KM}$, Valenstein $\mathrm{E}$, eds. Clinical neuropsychology. 2nd ed. New York: Oxford University Press, 1985:243-93.

2 Mesulam M-M. Attention, confusional states, and neglect. In: Mesulam M-M, ed. Principles of behavioral neurology. Philadelphia: FA Davis Co, 1985:125-68.

3 Heilman KM, Watson RT, Valenstein E, Damasio AR Localization of lesions in neglect. In Kertesz A, ed. Localization in neuropsychology. New York: Academic Press, 1983:471-92.

4 Vallar G, Perani D. The anatomy of unilateral neglect after right-hemisphere stroke lesions. A clinical/CT-scan corright-hemisphere stroke lesions. A clinical/CT-scan cor-

5 Latto $R$, Cowey A. Visual field defects after frontal eyefield lesions in monkeys. Brain Res 1971;30:1-24.

6 Rizzolatti G, Matelli M, Pavesi G. Deficits in attention and movement following the removal of postarcuate (area 6 ) and prearcuate (area 8) cortex in macaque monkeys. Brain 1983;106:655-73.

7 Heilman KM, Valenstein E. Frontal lobe neglect in man. Neurology 1972;22:660-4

8 Damasio AR, Damasio H, Chui HC. Neglect following damage to frontal lobe or basal ganglia. Neuropsychologia 1980;18:123-32.

9 Stein S, Volpe BT. Classical "parietal" neglect syndrome after subcortical right frontal lobe infarction. Neurology 1983.33:797.9.

10 Mesulam M-M. A cortical network for directed attention and unilateral neglect. Ann Neurol 1981;10:309-25.

11 Mesulam M-M. Large-scale neurocognitive networks and distributed processing for attention, language, and memory. Ann Neurol 1990;28:597-613.

12 Coslett HB, Bowers D, Fitzpatrick E, Haws B, Heilman KM. Directional hypokinesia and hemispatial inattention in neglect. Brain 1990;113:475-86.

13 Bisiach E, Geminiani G, Berti A, Rusconi ML. Perceptual and premotor factors of unilateral neglect. Neurology 1990;40:1278-81.

14 Tegnér $R$, Levander $M$. Through a looking glass. A new technique to demonstrate directional hypokinesia in unilateral neglect. Brain 1991;114:1943-51.

15 Binder J, Marshall R, Lazar R, Benjamin J, Mohr JP. Distinct syndromes of hemineglect. Arch Neurol 1992;49:1187-94.

16 Watson RT, Miller BD, Heilman KM. Nonsensory neglect. Ann Neurol 1978;3:505-8.

17 Heilman KM, Valenstein E. Mechanisms underlying hemispatial neglect. Ann Neurol 1979;5:166-70. 
18 Heilman KM, Bowers D, Coslett HB, Whelan H, Watson RT. Directional hypokinesia: prolonged reaction times for leftward movements in patients with right hemisphere lesions and neglect. Neurology 1985;35: 855-9.

19 Heilman KM, Bowers D, Valenstein E, Watson RT. Hemispace and hemispatial neglect. In: Jeannerod $M$, ed. Neurophysiological and neuropsychological aspects of spatial neglect. Amsterdam: Elsevier, 1987:115-50.

20 Daffiner KR, Ahern GL, Weintraub S, Mesulam M-M Dissociated neglect behavior following sequential strokes in the right hemisphere. Ann Neurol 1990;28:97-101.

21 Bottini G, Sterzi R, Vallar G. Directional hypokinesia in spatial hemineglect: a case study. I Neurol Neurosurg Psychiatry 1992;55:562-5.

22 Liu GT, Bolton AK, Price BH, Weintraub S. Dissociated perceptual-sensory and exploratory-motor neglect. F Neurol Neurosurg Psychiatry 1992;55:701-6.

23 Ishiai $S$, Sugishita $M$, Watabiki S, Nakayama T, Kotera M, Gono S. Improvement of left unilateral spatial neglect in a line extension task. Neurology 1994;44: 294-8.

24 Albert ML. A simple test of visual neglect. Neurology 1973;23:658-64.

25 Ishiai S, Sugishita M, Odajima N, Yaginuma M, Gono S, Kamaya T. Improvement of unilateral spatial neglect with numbering. Neurology 1990;40:1395-8.

26 Ishiai S, Furukawa T, Tsukagoshi H. Visuospatial processes of line bisection and the mechanisms underlyprocesses of line bisection and the mechanisms underly-

27 Schenkenberg T, Bradford DC, Ajax ET. Line bisection and unilateral visual neglect in patients with neurologic impairment. Neurology 1980;30:509-17.

28 Shirley E. A non-parametric equivalent of Williams' test for contrasting increasing dose levels of a treatment. Biometrics 1977;33:386-9.
29 Mijović D. Mechanisms of visual spatial neglect. Absence of directional hypokinesia in spatial exploration. Brain 1991;114:1575-93.

30 Ishiai S, Sugishita M, Mitani K, Ishizawa M. Leftward search in left unilateral spatial neglect. $f$ Neurol Neurosurg Psychiatry 1992;55:40-4.

31 Rizzolatti G, Gallese V. Mechanisms and theories of spatial neglect. In: Boller F, Grafman J, eds. Handbook of neuropsychology. Vol 1. Amsterdam: Elsevier, 1988: of neuropsyci.

32 Halligan PW, Marshall JC. Left visuo-spatial neglect: a meaningless entity? Cortex 1992;28:525-35.

33 Butter CM, Rapcsak S, Watson RT, Heilman KM. Changes in sensory inattention, directional motor neglect and "release" of the fixation reflex following a unilateral frontal lesion: a case report. Neuropsychologia 1988;26:533-45.

34 Milner B. Visually-guided maze learning in man: effects of bilateral hippocampal, bilateral frontal, and unilateral cerebral lesions. Neuropsychologia 1965;3:317-38.

35 Luria AR. Higher cortical functions in man. 2nd ed: New York: Basic Books, 1980:246-365.

36 Sandson J, Albert ML. Perseveration in behavioral neurology. Neurology 1987;37:1736-41.

37 Kwon SE, Heilman KM. Ipsilateral neglect in a patient following a unilateral frontal lesion. Neurology 1991;41: 2001-4.

38 Kinsbourne M. Mechanisms of unilateral neglect. In: Jeannerod M, ed. Neurophysiological and neuropsychological aspects of spatial neglect. Amsterdam: Elsevier, 1987: aspects

39 Marshall JC, Halligan PW. Line bisection in a case of visual neglect: psychophysical studies with implications for theory. Cogn Neuropsychol 1990;7:107-30.

40 Wolfe HK. On the estimation of the middle of lines. $A m \mathcal{F}$ Psychol 1923;34:313-58. 